\title{
Electroneurography in the evaluation of oxaliplatin-induced neuropathy in colorectal cancer patients
}

\author{
A. L. ZYGULSKA ${ }^{1, \star}$, M. BANACH ${ }^{2}$, K. KRZEMIENIECKI ${ }^{3}$ \\ ${ }^{1}$ Department of Oncology, Krakow University Hospital, Sniadeckich St. 10, 31-531 Krakow; ${ }^{2}$ Department of Neurology, Jagiellonian University, \\ Botaniczna St. 3, 31-531 Krakow, Poland; ${ }^{3}$ Department of Oncology, Jagiellonian University, Sniadeckich St. 10, 31-531 Krakow, Poland
}

*Correspondence: zygulska@poczta.onet.pl

Received January 29, 2016 / Accepted March 21, 2016

\begin{abstract}
Cold-induced neuropathy is the most observed side effect of oxaliplatin. Presence of neuropathy is routinely assessed by electroneurographical examination. The use of electroneurography has not been a part of typical oncological monitoring and treatment protocols, leading to untreated, irreversible damage to patients' peripheral nerves, undiagnosed for long periods of time. 36 colorectal cancer patients followed FOLFOX4 with/without bevacizumab or XELOX were enrolled between February 2013 and January 2015 in the study at the University Hospital Oncological Department, Krakow, Poland. Electroneurography was performed prior to the first cycle of chemotherapy and after the 4th cycle. 32 out of 36 enrolled patients completed neurological evaluation. Pre-treatment neurographic examination revealed presence of peripheral neuropathy in $10(31.25 \%)$ patients; $6(18.75 \%)$ had sensory neuropathy and 4 (12.5\%) had mixed, sensorimotor neuropathy. After treatment examination revealed significant increase in the number of neuropathic patients; presence of peripheral neuropathy was observed in 19 patients (59\%), sensory polyneuropathy was diagnosed in 10 patients (31.25\%) and mixed neuropathy was diagnosed in 9 patients (28.13\%). Early electrophysiological monitoring followed by a symptom dependent oxaliplatin regimen would be highly beneficial for patients undergoing oxaliplatin treatment, improving their well-being and positively affecting their life quality.
\end{abstract}

Key words: oxaliplatin, neuropathy, colorectal cancer, electroneurography

Oxaliplatin is a common cytotoxic agent in the treatment of colorectal cancer, used either as an adjuvant or palliative system therapy [1]. It belongs to the platinum class of drugs and, along with cisplatin and carboplatin, aside from treating affected tissue, exerts certain neurotoxic effects on peripheral nerves. Chemotherapy-induced neurotoxicity is often presented as a cold hypersensitivity of hands and feet, prolonged tingling and numbness and increased pain sensation, difficulties with walking leading, if not treated, to peripheral neuropathy $[2,3]$. Oxaliplatin-induced neuropathy might be diagnosed as reversible, acute paresthesia and dysesthesia in the extremities triggered or enhanced by exposure to cold. $82 \%$ of patients experience their neuropathy regress within 4 to 6 months. $41 \%$ of patients have complete recovery within 6 to 8 months $[4,5,6,7,8,9,10,11,12,13]$. Accumulative, often irreversible, chronic polyneuropathy induced by oxaliplatin in $13 \%$ to $20 \%$ of the patients and usually has a predictable clinical course $[6,8,9,13,14,15$,
16]. In this kind of polyneuropathy occur paresthesias and dysesthesias of gradually prolonged duration (between cycles), and increase in intensity with the cumulative dose and that eventually causes functional impairment and in consequence - the quality of life $[8,9]$. Moreover, exacerbation of oxaliplatin-induced neurotoxicity with the functional impairment following surgery are observed. It could be the result of peroperative hemolysis $[17,18]$.

The factors contributing to the development of long-term irreversible neuropathy remain unclear, however a growing number of studies indicate that certain forms of channelopathies and disturbance of normal axonal membrane potential might be responsible for neuropathy development $[3,19,20$, $21,22,23]$. Despite the prevalence of neurotoxicity symptoms in oxaliplatin treated patients, neurological examination has not been a part of standard cancer treatment protocol. Here in this paper we report high prevalence of neuropathy in oxaliplatin treated patients and underscore the benefits of 
early diagnosis and treatment of the peripheral nerve changes in colorectal cancer survivors.

\section{Material and methods}

A total of 36 colorectal cancer patients were enrolled between February 2013 and January 2015 for the study. Patients followed FOLFOX4 (folinic acid and 5-fluorouracil and oxaliplatin) with/without bevacizumab or XELOX (capecitabine and oxaliplatin) chemotherapy regimen at the University Hospital Oncological Department, Krakow, Poland. FOLFOX4 consisted of intravenous oxaliplatin 85 $\mathrm{mg} / \mathrm{m} 2$ on day 1 , leucovorin $200 \mathrm{mg} / \mathrm{m} 2$ on day 1,2 and $5 \mathrm{Fu}$ $400 \mathrm{mg} / \mathrm{m} 2$ in bolus on day 1,2 and $5 \mathrm{Fu} 600 \mathrm{mg} / \mathrm{m} 2$ in 22 hours on day 1,2. Treatment courses were repeated every 2 weeks for a maximum of 12 cycles. Bevacizumab $10 \mathrm{mg} /$ $\mathrm{kg}$ was administered intravenously on day 1 of each cycle. Chemotherapy regimen XELOX consisted of intravenous oxaliplatin $130 \mathrm{mg} / \mathrm{m} 2$ on day 1 and oral capecitabine $1000 \mathrm{mg} / \mathrm{m} 2$ twice daily on days 1-14 followed by a 7-day rest. Treatment courses were repeated every 3 weeks for a maximum of 8 cycles. Electroneurography was performed prior to the first cycle of chemotherapy and after the 4th cycle (when peripheral neuropathy risk increases). All patients underwent a complete neurological examination and a semi-structured questionnaire interview. The neurographic examination was carried out according to standard procedures using Viking Quest (Nicolet Biomedical Incorporated, Madison, WI, USA) following manufacturer guidelines. In all patients, neurographic examination of motor and sensory fibres of the following nerves: median, ulnar, peroneal, sural and tibial, was performed using standard stimulating sites [24]. The results of the examinations were compared with standard reference ranges established in our department and standard adopted from literature [24]. The study was approved by a local institutional ethical committee. Prior to the initiation of the study, written informed consent was obtained from all individual participants included in the study. Four patients did not complete the study due to collateral health issues or treatment discontinuation. Patient characteristics are presented in table 1.

Statistical analysis. Statistical analysis carried out using STATISTICA 10.PL. Comparison between groups were carried out using chi-squared test. The multiple logistic regression was used to estimate odds ratios (OR) with $95 \%$ confidence intervals $(95 \% \mathrm{CI})$. The results were considered statistically significant at $\mathrm{P}$ values of $=0.05$.

\section{Results}

Thirty two out of thirty six enrolled patients completed neurological evaluation. Four patients had only one examination; of those, in three cases, premature completion was due to the progression of the primary disease and in one case, the patient resigned from treatment continuation.
More than a half of all enrolled patients had a treatment delay. Neutropenia G3/G4 was the most common reason of chemotherapy interruption. Oxaliplatin dose was reduced for one fifth of all patients throughout the course of the treatment.

Adverse events were assessed at each cycle according to the National Cancer Institute Common Toxicity Criteria (NCICTC, version 4.03). Advanced symptoms of neuropathy (G3/ G4) were observed in 5 cases (15.6\%). Despite oxaliplatin dose reduction, symptoms of neuropathy persisted. In 4 out of 5 cases, oxaliplatin was omitted in the last few chemotherapy cycles. In 1 case the oxaliplatin dose was reduced. Premature treatment completion was necessary in 18 patients (56.25\%). Half of the patients (28.1\%) had progression of disease confirmed in the CT scans. Advanced symptoms of neuropathy G3/G4 in 4 patients (12.5\%), neutropenia G3/G4 (despite of neutropenia treatment) in 3 patients $(9.4 \%)$ and thrombocytopenia (despite of thromobocytopenia treatment) in 1 patient (3.1\%) were other reasons of premature treatment completion. Chemotherapy was completed at patient's request in 1 case (3.1\%). Delayed treatment was observed in 19 patients (59.4\%). Neutropenia G3/G4 (in 7 patients) and infection (in 4 patients) were the main reasons of the delay.

Thrombocytopenia G3 and neutropenia G3/G4 were observed in 1 (3.1\%) and 7 (21.9\%) of treated patients, respectively. The median cumulative dose was $686 \mathrm{mg} / \mathrm{m} 2$ and varied between 508 and $1000 \mathrm{mg} / \mathrm{m} 2$.

Electrophysiological examination. The diminution of amplitude of sensory nerve action potentials (SNAPs) and compound muscle action potentials (CMAPs) in lower limbs were most common and more advanced than the generally normal or moderate slowing of sensory and motor fibre conduction velocity. Lack of excitability in single nerves was diagnosed in 5 patients. We ascertained a lack of SNAPs: in the peroneal nerve ( 3 patients), in the ulnar nerve (1 patient) and lack of SNAP and CMAP in the peroneal nerve (1 patient). None of the patients showed signs of a conduction block.

Pre-treatment neurographic examination revealed presence of peripheral neuropathy in $10(31.25 \%)$ patients; $6(18.75 \%)$ had sensory neuropathy and $4(12.5 \%)$ had mixed, sensorimotor neuropathy. After treatment examination revealed significant increase in the number of neuropathic patients; presence of peripheral neuropathy was observed in 19 patients (59.4\%), sensory polyneuropathy was diagnosed in 10 patient $(31.25 \%)$ and sensorimotor neuropathy was diagnosed in 9 patients (28.13\%). None of the patients showed electrophysiological features of demyelination. In the remaining patients $(40.63 \%)$ neurographic examination remained within normal range. Results of the examination and the summary of neurographic findings are presented in table 2 and 3.

\section{Discussion}

Our study reports a high prevalence (59.4\%) of electrophysiological changes in the peripheral nerves of 
oxaliplatin treated patients. The results are consistent with earlier reports and emphasize the value of expanding cancer treatment monitoring protocols in cancer survivors by supplementing them with a routine neurological examination in order to prevent and/or alleviate oxaliplatin induced neurotoxicity and peripheral neuropathies $[2,3,25,26]$. Dorsal root ganglia sensory neurons, satellite cells, Schwann cells, neuronal and glial cells in the spinal cord are the most probably sites where occur neurotoxicity-induced chemotherapy [19]. The underlying mechanisms behind oxaliplatin toxicity remain unclear. However, DNA damage, alterations in cellular system repairs, mitochondria changes, increased intracellular reactive oxygen species, glutamate signalling, MAP-kinases and nociceptors ectopic activation are known as the most important reasons of the onset of oxaliplatin -induced peripheral neurotoxicity [19]. The organic cation transporter 2 expressed on dorsal root ganglia cells is responsible for multiple increasing of oxaliplatin uptake in cells. This phenomenon correlates with acute oxaliplatininduced neurotoxicity [27]. Recently, it emphasizes that an alterations on human motor and sensory axonal membrane $\mathrm{Na}(+)$ channels cause oxaliplatin-induced neurotoxicity [3, $19,21,22,23]$. On the basis of excitability studies performed before and immediately after oxaliplatin infusion show significant increases in refractoriness and relative refractory period postinfusion in all patients, consistent with an effect of oxaliplatin on axonal $\mathrm{Na}(+)$ channels. The patients with chronic neuropathy have greater changes. Following cessation of oxaliplatin treatment, $41 \%$ of patients have persistent symptoms and nerve conduction abnormalities consistent with the development of chronic neuropathy [23]. In our study premature treatment completion was in 4 patients $(12.5 \%)$ due to advanced symptoms of neuropathy. On the other hand, following oxaliplatin infusion, developing abnormalities are observed in the recovery cycle with refractoriness markedly increased. Continuing oxaliplatin infusions, changes developed consistent with axonal hyperpolarization, with proportional changes pre- and postoxaliplatin in normalized threshold [20].

Establish early clinical and neurophysiological markers of oxaliplatin-induced peripheral neuropathy is the aim of Velasco's et al. study. The patients presented a decrease in all nerve conduction studies, reported more acute neuropathic symptoms and received higher oxaliplatin cumulative dose. Neurological assessment and acute neuropathy symptoms meaning the over $30 \%$ decrease in sensory nerve action potential amplitude from the baseline in radial and dorsal sural nerves in nerve conduction studies at mid-treatment can indicate patients with risk of high-grade oxaliplatin-induced neurotoxicity [28]. Sensory axonal excitability techniques may be useful in monitoring for early signs of oxaliplatininduced neurotoxicity. Patients with severe neurotoxicity at the treatment completion demonstrated greater excitability changes than those left with mild or moderate neurotoxicity, suggesting that assessment of sensory excitability parameters may provide a sensitive biomarker of severity for oxaliplatininduced neurotoxicity $[3,29]$.

On databases PubMed and Cochrane established a relation between long term oxaliplatin-induced peripheral neuropathy (at least 12 months after completion of chemotherapy), severity of symptoms and higher cumulative dose of oxaliplatin $[4,29$, 30]. On the basis of neurological assessment, clinical neuropathy score and nerve conduction studies performed at baseline, the end of chemotherapy and two years after chemotherapy completion established that chronic oxaliplatin-induced neuropathy two years after discontinuing chemotherapy occurs very often. Almost $80 \%$ of patients have residual neuropathic symptoms, with distal loss of pin-prick sensibility and loss of vibration sensibility. There is observed correlation between severity of oxaliplatin-induced neuropathy two years and high severity of neuropathy at the end of chemotherapy [30,31]. Cumulative dose and infusion duration are critically associated with the incidence of this kind of neurotoxicity $[4,8,9$, $12,22,32]$. Factors such as a anemia, diabetes mellitus, high BMI (body mass index), hipomagnesemia are predisposing to the neuropathy from oxaliplatin $[33,34]$. On the other hand, the advanced age (69 years and more) of colorectal patients without any other significant co-morbidities receiving oxaliplatin does not influence the acute and cumulative oxaliplatin-induced neuropathy [35]. In our study alcohol abuse and the advanced age increase risk of neuropathy but these results are not statistically significant.

Pharmacogenomic methods are one of the methods to identify reasons in differences in oxaliplatin-induced neurotoxicity escalation within and/or after chemotherapy completion. The results of prospective, multicenter Argyriou's et al. study showns that nucleotide polymorphism of voltagegated sodium channels gene (SCN4A-rs2302237) is predictive factor of the severity of acute and the occurrence of chronic oxaliplatin-induced neuropathy. Furthermore, two single nucleotide polymorphisms (SCN4A-rs2302237 and SCN10Ars1263292) are significantly associated with an increased incidence of acute oxaliplatin-induced neuropathy [36]. In the other study identifies single-nucleotide polymorphisms in genes (involved in among others oxaliplatin metabolism) to predict oxaliplatin-induced peripheral neuropathy among patients treated with oxaliplatin based chemotherapy. The rs2230641 cyclin $\mathrm{H}(\mathrm{CCNH}) \mathrm{rs} 2230641 \mathrm{C} / \mathrm{C}$ and the ATPbinding cassette subfamily G, member 2 (ABCG2) rs3114018 A/A genotypes are associated with a higher risk of severe oxaliplatin-induced peripheral neuropathy. Moreover, the combination of CCNH C/C and/or the ABCG2 rs3114018 A/A genotypes results in a higher risk of grade 2-3 oxaliplatininduced peripheral neuropathy than those with the $\mathrm{CCNH}$ any $\mathrm{T}$ and $\mathrm{ABCG} 2$ any $\mathrm{C}$ genotypes. These findings of singlenucleotide polymorphisms allows to foresee higher probability of sereve oxaliplatin-induced peripheral neuropathy [1]. Other two trials estimating of polymorphisms in different genes as determinants of chronic oxaliplatin-induced peripheral neurotoxicity are negative $[37,38]$. 
Besides sensory peripheral neuropathy hematologic and gastrointestinal toxicities are frequent and moderate $[5,6]$. Neutropenia and thromocytopenia are the major hematologic toxicities [12,39]. Neutropenic febrile complications are rare [5]. The occurrence of side effects did not increase when oxaliplatin was added to fluorouracil-based regiments in our patients what is consistent with the literature data [5]. Gastrointestinal toxicities such as diarrhea, nausea, vomiting, stomatitis, abdominal pain are common, but controllable and rare long-lasting $[5,6$, $7,10,39,40]$. Older patients may have been more susceptible to dehydration, diarrhea, hypokalemia [39]. Hepatic failure with perisinusoidal fibrosis, peliosis or nodular regeneration hiperplasia with a progressive increase in gammaglutamyl transpeptidase and alkaline phosphatase is rare and severe side effect. In general liver function tests improve after oxaliplatin withdrawal. In some cases hepatic failure is lethal [41]. Hypersensitivity reactions related to oxaliplatin may manifest as facial flushing, rash/hives, tachycardia, dyspnoea, erythema, pruritus, fever, tongue swelling, headache, chills, weakness, vomiting, burning sensations, dizziness and oedema. These reactions are observed in approximately $12 \%$ of patients. In $1-2 \%$ of patients develop symptoms grade 3 or 4 [40, 42]. Furthermore, severe thrombocytopenia with immediate onset as a hypersensitivity reaction has been reported in literature [43]. All of the symptoms are reversible. Ocular toxicity included tunnel vision, visual loss with postural changes, altered color vision are rare and reversible [44, 45]. Dysphonia with acute onset is other rare symptom after the administration of oxaliplatin [46]. Both ocular toxicity and dysphonia impair transiently the quality of life. Rare, isolated cases of pulmonary fibrosis and fatal diffuse alveolar damage induced by oxaliplatin are reported in literature $[47,48,49]$. Reversible urinary retension and Lhermitte sign after the higher than $1000 \mathrm{mg}$ cumulative dose of oxaliplatin [32]. Toxicity was mild and generally acceptable in presented group of the patients. Hematological toxicity G3/G4 occured in 8 patients. Gastrointestinal toxicities (nausea, diarrhea, vomiting) G1/G2 were reported in 14 patients. Advanced symptoms of neuropathy G3/G4 with the quality of life impairment was observed in 5 cases. None of the patients did not report any other side effects.

Early diagnosis of the neurotoxicity and reductions in oxaliplatin dose or alteration of chemotherapy schedule can prevent against chronic symptoms which in consequence can be persisted and effect on the quality of life [50,51]. Despite this procedure efficacy of oxaliplatin therapy is safely maintained. Effective medicaments against oxaliplatin-induced neurotoxicity are topical pain relievers, such as baclofen/amitriptyline/ ketamine gel, and serotonin and norepinephrine reuptake inhibitors, such as venlafaxine and duloxetine [52, 53]. Amifostine is a radioprotective drug that has oto- and neuroprotector effects to cisplatin injury and protect against cyclophosphamide-induced taste loss [54]. In preclinical study showed neuroprotection effect of amifostine. Further clinical trials are necessary to evaluate in patients treated with oxaliplatin regiments [55]. On the other hand, there are disappointed results from the current trial where observed a lack of benefit for Vitamin $\mathrm{E}$ in prophylaxis oxaliplatininduced peripheral neuropathy [56]. A nonpharmacological therapy cutaneous electrostimulation seems to be potentially effective in the treatment of oxaliplatin-induced neurotoxicity [52]. The earlier recommendations for the management of the acute and chronic neuropathy induced oxaliplatin include use of neuromodulatory agents, such as intravenous calcium and magnesium infusions [52, 57]. In more recent Han's et al. double blind crossover study revealed that oxaliplatin given with $\mathrm{Ca} / \mathrm{Mg}$ or placebo has the same plasma pharmacokinetics of intact anticancer drug and free platinum. Moreover, electromyography motor nerve hyperexcitability scores is similar with $\mathrm{Ca} / \mathrm{Mg}$ or placebo. In addition, frequency of acute neurotoxicity symptoms are not differ between $\mathrm{Ca} / \mathrm{Mg}$ and placebo [58].

Summarizing, oxaliplatin-induced neuropathy is a common side effect of oxaliplatin therapy in colorectal cancer patients. Early electrophysiological monitoring followed by a symptom dependent oxaliplatin regimen adjustment and early introduction of anti-neuropathy preventive measures would be highly beneficial for patients undergoing oxaliplatin treatment, improving their well-being and positively affecting their life quality. Based on the results of our and other's studies, we postulate that the routine neurographical examination should be a part of a standard colorectal cancer therapy protocol.

Acknowledgments: Authors thank the all patients participated in the study.

\section{References}

[1] CUSTODIO A, MORENO-RUBIO J, APARICIO J, GALLEGO-PLAZAS J, YAYA R et al. Pharmacogenetic predictors of severe peripheral neuropathy in colon cancer patients treated with oxaliplatin-based adjuvant chemotherapy: a GEMCAD group study. Ann Oncol 2014; 25: 398-403. http://dx.doi. org/10.1093/annonc/mdt546

[2] PARK SB, GOLDSTEIN D, KRISHNAN AV, LIN CS, FRIEDLANDER ML et al. Chemotherapy-induced peripheral neurotoxicity: A critical analysis. CA Cancer J Clin 2013; doi: 10.1002/caac.21204.

[3] PARK SB, LIN CS, KIERNAN MC. Nerve excitability assessment in chemotherapy-induced neurotoxicity. J Vis Exp 2012; doi: 10.3791/3439. http://dx.doi.org/10.3791/3439

[4] EXTRA JM, MARTY M, BRIENZA S, MISSET JL. Pharmacokinetics and safety profile of oxaliplatin.Semin Oncol 1998; 2 Suppl 5: 13-22.

[5] HALLER DG. Safety of oxaliplatin in the treatment of colorectal cancer. Oncology (Williston Park) 2000; 12 Suppl 11: 15-20.

[6] BECOUARN Y, YCHOU M, DUCREUX M, BOREL C, BERTHEAULT-CVITKOVIC F et al. Phase II trial of oxaliplatin as first-line chemotherapy in metastatic colorectal cancer patients. Digestive Group of French Federation of Cancer Centers. J Clin Oncol 1998; 16: 2739-2744. 
[7] BUGAT R. Oxaliplatin tolerance in the treatment of metastatic colorectal cancers. Bull Cancer 2001; 88: S45-S49.

[8] CHOI J, KONG K, MOZAFFAR T, HOLCOMBE RF. Delayed oxaliplatin-associated neurotoxicity following adjuvant chemotherapy for stage III colon cancer. Anticancer Drugs 2006; 17: 103-105. http://dx.doi.org/10.1097/01. cad.0000185185.64980.70

[9] GAMELIN L, BOISDRON-CELLE M, MOREL A, GAMELIN E. Oxaliplatin neurotoxicity. Bull Cancer 2006; 93 Suppl 1: S17-S22.

[10] CASSIDY J, MISSET JL. Oxaliplatin-related side effects: characteristics and management. Semin Oncol 2002; 5 Suppl 15: 11-20. http://dx.doi.org/10.1053/sonc.2002.35524

[11] MAS MOREY P, CHOLVI LLOVELL M, NIGORRA CARO M, NICOLAS PICO J, VILANOVA BOLTO M. Oxaliplatin-associated neurotoxicity in clinical practice. Farm Hosp 2012; 36: 336-342. http://dx.doi.org/10.1016/j. farma.2011.03.010

[12] JARDIM DL, RODRIGUES CA, NOVIS YA, ROCHA VG, HOFF PM. Oxaliplatin- related thrombocytopenia. Ann Oncol 2012; 23: 1937-1942. http://dx.doi.org/10.1093/annonc/ $\underline{\mathrm{mds} 074}$

[13] LAND SR, KOPEC JA, CECCHINI RS, GANZ PA, WIEAND HS et al. Neurotoxicity from oxaliplatin combined with weekly bolus fluorouracil and leucovorin as surgical adjuvant chemotherapy for stage II and III colon cancer: NSABP C-07. Clin J Oncol 2007; 25: 2205-211. http://dx.doi.org/10.1200/ ICO.2006.08.6652

[14] BEIJERS AJ, MOLS F, VREUGDENHIL G. A systematic review on chronic oxaliplatin-induced peripheral neuropathy and the relation with oxaliplatin administration. Support Care Cancer 2014; 22: 1999-2007. http://dx.doi.org/10.1007/ s00520-014-2242-Z

[15] GENT P, MASSEY K. An overview of chemotherapy-induced peripheral sensory neuropathy, focusing on oxaliplatin. Int J Palliat Nurs 2001; 7: 354-359. http://dx.doi.org/10.12968/ ijpn.2001.7.7.9020

[16] MCWHINNEY SR, GOLDBERG RM, MCLEOD HL. Platinum neurotoxicity pharmacogenetics. Mol Cancer Ther 2009; 8: 10-16. http://dx.doi.org/10.1158/1535-7163.MCT$\underline{08-0840}$

[17] COURNEDE A, RIES P, RICHARD K, GUILLAIN A, DAHAN L et al. Oxaliplatin neurotoxicity: a report of three cases with post-operative exacerbation. Gastroenterol Clin Biol 2005; 29: 461-464. http://dx.doi.org/10.1016/S0399-8320(05)80817-6

[18] GORNET JM, SAVIER E, LOKIEC F, CVITKOVIC E, MISSET JL et al. Exacerbation of oxaliplatin neurosensory toxicity following surgery. Ann Oncol 2002; 13: 1315-1318. http://dx.doi.org/10.1093/annonc/mdf254

[19] CAROZZI VA, CANTA A, CHIORAZZI A, CAVALETTI G. Chemotherapy-induced peripheral neuropathy: What do we know about mechanisms? Neurosci Lett 2014; [Epub ahead of print].

[20] PARK SB, LIN CS, KRISHNAN AV, GOLDSTEIN D, FRIEDLANDER ML et al. Utilizing natural activity to dissect the pathophysiology of acute oxaliplatin-induced neuropathy.
Exp Neurol 2011; 227: 120-127. http://dx.doi.org/10.1016/j. expneurol.2010.10.002

[21] PARK SB, LIN CS, KRISHNAN AV, GOLDSTEIN D, FRIEDLANDER ML et al. Dose effects of oxaliplatin on persistent and transient $\mathrm{Na}+$ conductances and the development of neurotoxicity. PloS one 2011; 6: e18469. http://dx.doi.org/10.1371/ journal.pone.0018469

[22] PARK SB, KRISHNAN AV, LIN CS, GOLDSTEIN $D$, FRIEDLANDER $M$ et al. Mechanisms underlying chemotherapy-induced neurotoxicity and the potential for neuroprotective strategies. Curr Med Chem 2008; 15: 30813094. http://dx.doi.org/10.2174/092986708786848569

[23] KRISHNAN AV, GOLDSTEIN D, FRIEDLANDER M, KIERNAN MC. Oxaliplatin and axonal Na+ channel function in vivo. Clin Cancer Res 2006; 12: 4481-4484. http://dx.doi. org/10.1158/1078-0432.CCR-06-0694

[24] OH SJ. Clinical electromyography: nerve conduction studies. 3rd ed. Baltimore: Lippincott, Williams \& Wilkins 2003.

[25] ARGYRIOU AA, POLYCHRONOPOULOS P, ICONOMOU G, KOUTRAS A, MAKATSORIS T et al. Incidence and characteristics of peripheral neuropathy during oxaliplatin-based chemotherapy for metastatic colon cancer. Acta Oncol 2007; 46: 1131-1137. http://dx.doi.org/10.1080/02841860701355055

[26] KRISHNAN AV, GOLDSTEIN D, FRIEDLANDER M, KIERNAN MC. Oxaliplatin-induced neurotoxicity and the development of neuropathy. Muscle Nerve 2005; 32: 51-60. http://dx.doi.org/10.1002/mus.20340

[27] SPROWL JA, CIARIMBOLI G, LANCASTER CS, GIOVINAZZO H, GIBSON AA et al. Oxaliplatin-induced neurotoxicity is dependent on the organic cation transporter OCT2. Proc Natl Acad Sci USA 2013; 110: 11199-11204. http://dx.doi.org/10.1073/pnas.1305321110

[28] VELASCO R, BRUNA J, BRIANI C, ARGYRIOU AA, CAVALETTI $G$ et al. Early predictors of oxaliplatin-induced cumulative neuropathy in colorectal cancer patients. J Neurol Neurosurg Psychiatry 2014; 85: 392-398. http://dx.doi. org/10.1136/jnnp-2013-305334

[29] PARK SB, LIN CS, KRISHNAN AV, GOLDSTEIN D, FRIEDLANDER ML et al. Oxaliplatin-induced neurotoxicity: changes in axonal excitability precede development of neuropathy. Brain 2009; 132: 2712-2723. http://dx.doi. org/10.1093/brain/awp219

[30] PARK SB, LIN CS, KRISHNAN AV, GOLDSTEIN D, FRIEDLANDER ML et al. Long-term neuropathy after oxaliplatin treatment: challenging the dictum of reversibility. Oncologist 2011; 16: 708-716. http://dx.doi.org/10.1634/ theoncologist.2010-0248

[31] BRIANI C, ARGYRIOU AA, IZQUIERDO C, VELASCO R, CAMPAGNOLO $\mathrm{M}$ et al. Long-term course of oxaliplatininduced polyneuropathy: a prospective 2-year follow-up study. J Peripher Nerv Sys 2014; 19: 299 -306. http://dx.doi. org/10.1111/jns.12097

[32] TAIEB S, TRILLET-LENOIR V, RAMBAUD L, DESCOS L, FREYER G. Lhermitte sign and urinary retention: atypical presentation of oxaliplatin neurotoxicity in four patients. Cancer 2002; 94: 2434-2440. http://dx.doi.org/10.1002/ cncr. 10500 
[33] OTTAIANO A, NAPPI A, TAFUTO S, NASTI G, DE DIVITIIS C et al. Diabetes and body Mass Index are associated with neuropathy and prognosis in colon cancer patients treated with capecitabine and oxaliplatin adjuvant chemotherapy. Oncology 2016 [Epub ahead of print]. http://dx.doi. org/10.1159/000442527

[34] SHAHRIANI-AHMADI A, FAHIMI A, PAYANDEH M, SADEGHI M. Prevalence of oxaliplatin-induced chronic neuropathy and influencing factors in patients with colorectal cancer in Iran. Asia Pac J Cancer Prev 2015; 16: 7603-7606. http://dx.doi.org/10.7314/APJCP.2015.16.17.7603

[35] ARGYRIOU AA, BRIANI C, CAVALETTI G, BRUNA J, ALBERTI $P$ et al. Advanced age and liability to oxaliplatininduced peripheral neuropathy: post hoc analysis of a prospective study. Eur J Neurol 2013; 20: 788-794. http:// dx.doi.org/10.1111/ene.12061

[36] ARGYRIOU AA, CAVALETTI G, ANTONACOPOULOU A, GENAZZANI GG, BRIANI C et al. Voltage-gated sodium channel polymorphisms play a pivotal role in the development of oxaliplatin-induced peripheral neurotoxicity: results from a prospective multicenter study. Cancer 2013; 119: 3570-3577. http://dx.doi.org/10.1002/cncr.28234

[37] RUZZO A, GRAZIANO F, GALLI F, GIACOMINI E, FLORIANI I et al. Genetic markers for toxicity of adjuvant oxaliplatin and fluoropyrimidines in the phase III TOSCA trial in high-risk colon cancer patients. Sci Rep 2014; doi: 10.1038/ srep06828. http://dx.doi.org/10.1038/srep06828

[38] TERRAZZIONO S, ARGYRIOU AA, CARGNIN S, ANTONACOPOULOU AG, BRIANI C et al. Genetic determinants of chronic oxaliplatin-induced peripheral neurotoxicity: a genome-wide study replication and meta-analysis. J Peripher Nerv Syst 2015; [Epub ahead of print]. http://dx.doi. org/10.1111/jns. 12110

[39] IBRAHIM A, HIRSCHFELD S, COHEN MH, GRIEBEL DJ, WILLIAMS GA et al. FDA drug approval summaries: oxaliplatin. Oncologist 2004; 9: 8-12. http://dx.doi.org/10.1634/ theoncologist.9-1-8

[40] HOFF PM, SAAD ED, COSTA F, COUTINHO AK, CAPONERO R et al. Literature review and practical aspects on the management of oxaliplatin-associated toxicity. Clin Colorectal Cancer 2012; 11: 93-100. http://dx.doi.org/10.1016/j. clcc.2011.10.004

[41] AROTCARENA R, CALES V, BERTHELEMY P, PARENT Y, MALET $M$ et al. Severe sinusoidal lesions: a serious and overlooked complication of oxaliplatin-containing chemotherapy? Gastroenterol Clin Biol 2006; 30: 1313-1316. http:// dx.doi.org/10.1016/S0399-8320(06)73542-4

[42] SAIF MW. Hypersensitivity reactions associated with oxaliplatin. Expert Opin Drug Saf 2006; 5: 687-694. http://dx.doi. org/10.1517/14740338.5.5.687

[43] MASON JM, REES GJ. Oxaliplatin-induced acute thrombocytopenia. J Oncol Pharm Pract 2011; 17: 433-435. http:// dx.doi.org/10.1177/1078155210381287

[44] O'DEA D, HANDY CM, WEXLER A. Ocular changes with oxaliplatin. Clin J Oncol Nurse 2006; 10: 227-229. http:// dx.doi.org/10.1188/06.CJON.227-229
[45] MESQUIDA M, SANCHEZ-DALMAU B, ORTIZ-PEREZ S, PELEGRIN L, MOLINA-FERNANDEZ JJ et al. Oxaliplatinrelated ocular toxicity. Case Rep Oncol 2010; 3: 423-427. http://dx.doi.org/10.1159/000322675

[46] BERRETTA M, TAIBI R, BEARZ A, LA MURA N, BERRETTA $S$ et al. Dysphonia as an unusual toxic event of oxaliplatin-based chemotherapy. J Chemother 2004; 16: 595-598. http://dx.doi.org/10.1179/joc.2004.16.6.595

[47] SHAH A, UDWADIA ZF, ALMEL S. Oxaliplatin-induced lung fibrosis. Indian J Med Paediatr Oncol 2009; 30: 116-118. http://dx.doi.org/10.4103/0971-5851.64259

[48] WATKINS J, SLADE JH, PHAN A, ENG C, WEISSFERDT A et al. Fatal diffuse alveolar damage associated with oxaliplatin administration. Clin Colorectal Cancer 2011; 10: 198-202. http://dx.doi.org/10.1016/j.clcc.2011.03.019

[49] PROCHILO T, ABENI C, BERTOCCHI P, ZANIBONI A. Oxaliplatin-induced lung toxicity. Case report and review of the literature. Curr Drug Saf 2012; 7: 179-182. http://dx.doi. org/10.2174/157488612802715672

[50] ZEDAN AH, HANSEN TF, FEX SVENNINGSEN A, VILHOLM OJ. Oxaliplatin-induced neuropathy in colorectal cancer: many questions with few answers. Clin Colorectal Cancer 2014; 13: 73-80. http://dx.doi. org/10.1016/j.clcc.2013.11.004

[51] VELASCO R, BRUNA J. Chemotherapy-induced peripheral neuropathy: an unsolved issue. Neurologia 2010; 25: 116-131. http://dx.doi.org/10.1016/S0213-4853(10)70036-0

[52] PACHMAN DR, BARTON DL, WATSON JC, LOPRINZI CL. Chemotherapy-induced peripheral neuropathy: prevention and treatment. Clin Pharmacol Ther 2011; 90: 377-387. http://dx.doi.org/10.1038/clpt.2011.115

[53] KUS T, AKTAS G, ALPAK G, KALENDER ME, SEVINC A et al. Efficacy of venlafaxine for the relief of taxane and oxaliplatin-induced acute neurotoxicity: a single-center retrospective case-control study. Support Care Cancer 2015 [Epub ahead of print].

[54] MUKHERJEE N, CARROLL BL, SPEES JL, DELAY ER. Pre-treatment with amifostine protects against cyclophosphamide-induced disruption of taste in mice. PLoS ONE 2013; doi: 10.1371/journal.pone. 0061607

[55] CERESA C, AVAN A, GIOVANETTI E, GELDOF AA, AVAN A et al. Characterization of and protection from neurotoxicity induced by oxaliplatin, bortezomib and epothilone-B. Anticancer Res 2014; 34: 517-523.

[56] SALEHI Z, ROAYAEI M. Effect of vitamin E on oxaliplatininduced peripheral neuropathy prevention: A randomized controlled trial. Int J Prev Med 2015; doi: 10.4103/20087802.169021. http://dx.doi.org/10.4103/2008-7802.169021

[57] SAIF MW, REARDON J. Management of oxaliplatin-induced peripheral neuropathy. Ther Clin Risk Manag 2005; 1: 249258.

[58] HAN CH, KHWAOUNJOO P, KILFOYLE DH, HILL A, MCKEAGE MJ. Phase I drug-interaction study of effects of calcium and magnesium infusions on oxaliplatin pharmacokinetics and acute neurotoxicity in colorectal cancer patients. BMC Cancer 2013; doi: 1186/1471-2407-13-495 